Historia
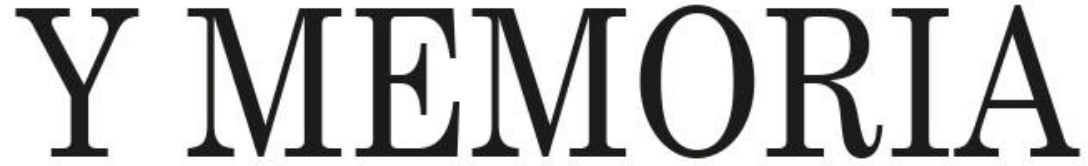

ISSN: 2027-5137

Enero - Junio, Año 2021 - Tunja, Colombia

Migración en tiempos de la Segunda Guerra Mundial. El caso de una mujer Judía a Tucumán

https:/doi.org/10.19053/20275137.n22.2021.9764

Vanesa Teitelbaum

Páginas 285-321

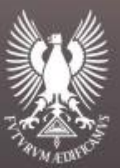




\title{
Migración en tiempos de la Segunda guerra Mundial. El caso de una mujer judía a Tucumán*
}

\author{
Vanesa Teitelbaum ${ }^{1}$ \\ Universidad Nacional de Tucumán \\ Consejo Nacional de Investigaciones \\ Científicas y Técnicas - Argentina
}

Recepción: 11/07/2019

Evaluación: 02/10/2019

Aprobación: 07/02/2020

Artículo de Investigación e Innovación

https:/doi.org/10.19053/20275137.n22.2021.9764

\section{Resumen}

El propósito de este artículo es analizar el movimiento migratorio de refugiados judíos derivado de la Segunda Guerra Mundial y de la violencia nazi. Para ello, el trabajo reconstruye y examina la travesía migratoria de una mujer judía que escapó de Polonia y se refugió en Argentina, al promediar el año 1941.

\footnotetext{
* El artículo es producto del plan de trabajo dirigido que desarrollo como Investigadora Adjunta del Consejo Nacional de Investigaciones Científicas y Técnicas (CONICET), con sede en el ISES (CONICET/UNT), Tucumán, Argentina. Dicha investigación está dirigida al análisis de la inmigración y el asociacionismo judío en Tucumán (desde el novecientos hasta la segunda posguerra).

1 Doctora en Historia por El Colegio de México. Investigadora Adjunta del Consejo Nacional de Investigaciones Científicas y Técnicas (CONICET), con sede en el ISES (CONICET/UNT), Tucumán, Argentina. Docente a cargo de cátedra de «Historia social y política argentina” en la Facultad de Filosofía y Letras de la Universidad Nacional de Tucumán. Algunas de sus publicaciones más recientes son: «Mujeres, migración y exilio (Argentina, del país aluvial a los tiempos de guerra),» EIAL, Estudios Interdisciplinarios de América Latina y el Caribe, (en prensa, 2019), «Mundo del idish y asociaciones culturales judías en Tucumán. Una reflexión a partir de la visita de Zalman Reisen en 1932,» Cuadernos Judaicos, Centro de Estudios Judaicos, Facultad de Filosofía y Humanidades, Universidad de Chile, (en prensa, 2019) y Las comunidades de inmigrantes en Tucumán: mundo asociativo, fiestas y trabajo (Buenos Aires: Imago Mundi, 2017) $\bowtie$ vteitel@yahoo.com [ㄱ https://orcid.org/00000003-0906-8872.
} 
Desde una perspectiva de historia social y con una metodología cualitativa, el trabajo explora, a través de su diario de viaje, sus sentimientos y reflexiones en torno a los familiares que permanecieron en Europa, las dramáticas consecuencias de la guerra y las migraciones forzosas. Argumento que, tanto sus expresiones de agradecimiento por las ayudas recibidas en su trayectoria migratoria como, en contraste, sus opiniones negativas frente a determinadas actitudes y políticas (por ejemplo las de la Unión Soviética) recorrieron sus experiencias de migración, situadas, además, en una etapa clave del avance del terror nazi, antes del establecimiento de la denominada «Solución Final». Otro de los supuestos que subyace en este trabajo gira en torno a los sentimientos de dolor y el peso que significaron para ella haber sido la única de su familia que se salvó, preocupación común a otros refugiados y sobrevivientes judíos de la Shoá.

Palabras claves: Shoá, Polonia, migración, nazismo, refugiados judíos.

\title{
Migration in times of the Second World War. The case of a Jewish woman in Tucumán.
}

\begin{abstract}
The purpose of this article is to analyse the migratory movement of Jewish refugees caused by the Second World War and Nazi violence. For this, the present work reconstructs and examines the journey of a Jewish woman who escaped from Poland and who sought refuge in Argentina, around the year 1941. From the perspective of social history and with a qualitative methodology, the work explores, though her travel log, her feelings and reflections regarding the relatives who had remained in Europe, the dramatic consequences of the war and the forced migrations. Her expressions of gratitude for the help she received during her migratory journey, as well as, in contrast, her negative opinions about certain attitudes and policies (for example those of the Soviet Union) draw upon her migration experiences, set in a key phase of the advancement of the Nazi terror, before the establishment
\end{abstract}


of the so called «Final solution». Another situation that underlies this work revolves around the feeling of sorrow and the weight that came from her being the only member of her family that was saved, a concern common to other refugees and Jewish survivors of the Shoá.

Key words: Shoá, Poland, migration, Nazism, Jewish refugees.

\section{Migration aux temps de la Seconde Guerre Mondiale. Le cas d'une femme juive à Tucumán.}

\section{Résumé}

Cet article se propose d'analyser le mouvement migratoire de réfugiés juifs dérivé de la Seconde Guerre Mondiale et de la violence nazi. Pour ce faire, ce texte reconstitue et examine la traversée migratoire d'une femme juive qui avait échappé de Pologne pour se réfugier en Argentine en 1941. Dans une perspective d'histoire sociale et avec une méthodologie qualitative, cet article explore, à partir du journal intime de la femme en question, les sentiments et les réflexions autour des gens de sa famille ayant resté en Europe, les conséquences dramatiques de la guerre et les migrations forcées. Les expressions de reconnaissance pour l'aide qu'elle a reçu pendant sa migration, ainsi que les opinions défavorables qu'elle portait sur quelques décisions politiques (par exemple, celles de l'Union Soviétique) traversent ses expériences de migration, situées dans un moment clé de l'avance de l'horreur nazi, peu avant la «la solution finale». Par ailleurs, ce texte revient sur les sentiments de douleur concernant le fait qu'elle a été la seule de sa famille à être sauvée, une préoccupation commune à d'autres réfugiés et survivants juifs de la Shoa.

Mots-clés: Shoa, Pologne, migration, nazisme, réfugiés politiques. 


\section{Introducción}

Son abundantes los testimonios y los trabajos académicos que abordaron el tema de la Shoá, la Segunda Guerra Mundial y los judíos en Argentina; sin embargo, la gran mayoría de los registros y de las investigaciones se concentraron en Buenos Aires, lo cual resulta lógico al tratarse de la provincia que alberga al grueso de la comunidad judía del país. Menos conocidas, en cambio, resultan las experiencias de aquellos hombres, mujeres y niños que escaparon de Europa en tiempos del terror nazi y, tras llegar al país, se dirigieron al interior, donde construyeron sus vidas y permanecieron hasta el final de sus días.

Una de estas historias poco conocidas o, mejor dicho, ignoradas completamente fue la de Nechoma Zaluski (1914-1994), quien consiguió escapar de Polonia a través de un riesgoso y largo viaje que comenzó a finales de 1939 cuando se dirigió por la frontera hacia Lituania y concluyó al llegar a la Argentina un 9 de julio de 1941, fecha de gran contenido simbólico para el país que festejaba su Independencia. Tras su arribo al puerto de Buenos Aires, se trasladó rápidamente a Tucumán, donde vivía la familia de su marido que había migrado también desde Polonia poco antes y fue allí, en esa provincia del noroeste argentino, en donde logró rearmar su vida y destacarse por su activa participación en la comunidad judía local.

Desde un enfoque de historia social, abierto a su vez a los fenómenos culturales y políticos, el trabajo analiza, a través de una metodología principalmente cualitativa, un conjunto de fuentes que incluyen las agendas personales de 


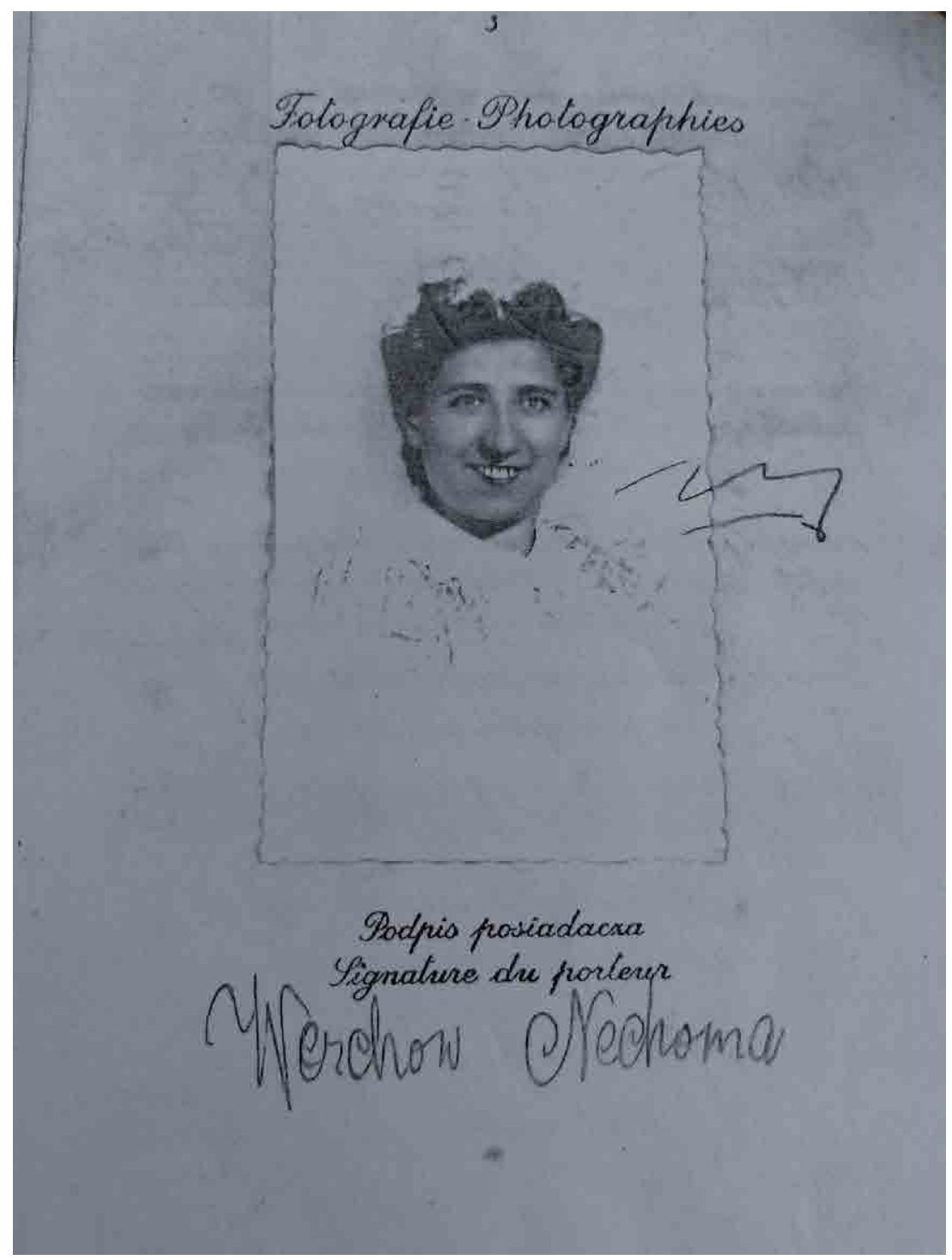

Foto 1. Fotografía del Pasaporte de Nechoma con su apellido de casada Werchow Fuente: Archivo familiar (privado) de Nechoma Z., Tucumán- Argentina. 
Nechoma, documentos migratorios, fotos y, en especial, el manuscrito que redactó en idish, pensado como un diario de viaje y cuya riqueza para esta investigación es invaluable ${ }^{2}$. Estos documentos se completaron y complementaron con la consulta de leyes, decretos y mapas de la época, material que permitió situar esta historia en un contexto más amplio. Grosso modo, podemos señalar que la información contenida en estas fuentes posibilitó una aproximación micro-analítica de la inmigración judía, perspectiva que se conjugó con el examen de la producción historiográfica, para recrear los distintos escenarios en los cuales transcurrió la trayectoria migratoria analizada y buscar las conexiones con otros recorridos en la época bajo estudio ${ }^{3}$.

El artículo está organizado de la siguiente manera: Reconstruye y examina el viaje de Nechoma a la Argentina, tarea que incluyó la revisión de otros itinerarios de huida en tiempos del nazismo. Paralelamente, el trabajo explora a través de su narrativa personal, plasmada sobre todo en su diario de viaje (cuya escritura cubre el periodo 1939 a 1946)

\footnotetext{
2 Estoy sumamente agradecida con la Arq. Diana Mizrahi, quien tuvo la generosidad de compartir conmigo este material, al cual me referiré como archivo familiar (privado) Nechoma Z., Tucumán-Argentina (AFPN). Respecto al diario de viaje (manuscrito) de Nechoma es importante señalar que éste se refiere al periodo comprendido entre diciembre de 1939 y noviembre de 1946. Asimismo, quisiera apuntar que denominé "África Marú» a la fuente debido a que éste era el nombre que el texto llevaba escrito en la primera hoja y que, como veremos más adelante en este artículo, se refiere al nombre del barco que la transportó en 1941 en su viaje a la Argentina. La paginación es propia y se realizó para facilitar el citado de la fuente. La traducción del idish al castellano fue realizada por Lucas Fiszman.

3 En esa tónica, fueron sugerentes las consideraciones de María Bjerg, quien reconstruyó la vida de cinco inmigrantes «indagando en lo pequeño y leyendo las experiencias individuales a la luz del contexto», María Bjerg, Historias de la inmigración en la Argentina (Buenos Aires: Edhasa, 2009), 15. Siguiendo también a esta historiadora, podemos recuperar sus señalamientos en torno a la importancia de la lectura bibliográfica, la cual en su caso, le permitió recrear «aristas del ambiente que no emergían de los relatos de [sus] entrevistados» y "dilucidar las conexiones entre los destinos individuales y los contextos en los cuales transcurrieron». Como sostiene Bjerg, la aproximación micro-analítica se suma al enfoque panorámico de la inmigración y "contribuye con nuevos saberes no solo aportando datos más numerosos y finos, sino dando lugar a configuraciones más complejas que, a partir de la multiplicidad de destinos particulares, habilitan nuevas lecturas (en general, más esclarecedoras) del conjunto». María Bjerg, El Viaje de los niños. Inmigración, infancia y memoria en la Argentina de la Segunda Posguerra (Buenos Aires: Edhasa, 2012), 12-17.
} 
sus sentimientos y reflexiones en torno a los familiares que permanecieron en Polonia, las dramáticas consecuencias de la guerra y las migraciones forzosas.

Argumento en estas páginas que, tanto sus expresiones de agradecimiento por las ayudas recibidas en su trayectoria migratoria como, en contraste, sus opiniones negativas frente a determinadas actitudes y políticas (por ejemplo las de la Unión Soviética) recorrieron sus experiencias de migración, situadas, además, en una etapa clave del avance del terror nazi; concretamente entre finales de 1939 y mediados de 1941, antes del establecimiento de la denominada «Solución Final».

Otro de los supuestos que subyace en este trabajo gira en torno a los sentimientos de dolor y el peso que significaron para ella haber sido la única de su familia que se salvó. En esa tónica, me sirvieron las sugerencias presentes en buena parte de la bibliografía sobre el tema de la Shoá acerca de cómo uno de los principales interrogantes que signaron las experiencias de los sobrevivientes ${ }^{4}$ fue por qué ellos se salvaron, en lugar de otros miembros de su familia o de su ámbito de conocidos y amigos ${ }^{5}$. Esta pregunta, sumada a la atrocidad y amplitud del exterminio, alentaba la mirada hacia el pasado al que volvían buscando respuestas. En este recorrido, transitado una y otra vez por las víctimas, afloraron tanto aspectos comunes como facetas divergentes que permitieron a los investigadores configurar las explicaciones sobre la destrucción del pueblo judío en Europa ${ }^{6}$.

\footnotetext{
4 Una definición amplia de sobrevivientes que incluye no solo a quienes pasaron por los campos de exterminio, sino también «a quienes estuvieron en campos de trabajo, en guetos, escondidos en bosques, los que participaron en sabotajes, correos, quienes asumieron una identidad falsa, los que lograron huir», propone Diana Wang, Los niños escondidos. Del Holocausto a Buenos Aires (Buenos Aires: Marea Editorial, 2018 [Primera edición 2004]), 16.

5 Por ejemplo, Wang sostiene que «la pregunta por la propia salvación es una constante en todos los sobrevivientes», Wang, Los niños escondidos, 241-243. En los libros de testimonios de sobrevivientes se pueden observar ejemplos en ese sentido. Por ejemplo, Roberto Raschella y Mariano Fiszman, La historia que nunca les conté. El libro de Gisela. Polonia, 1943-1944 (Buenos Aires: Grupo Editorial Norma, 2005), 11, Eugenia Unger, Holocausto. Lo que el tiempo no borró (Buenos Aires: Distal, 1996), 7.

6 No pretendo referirme a la totalidad de la vasta producción sobre el tema. Únicamente quisiera mencionar algunos estudios sugerentes para esta investigación, por ejemplo,
} 
Para el desarrollo de esta investigación, me apoyo, además, en las contribuciones provenientes de un campo de análisis especialmente fértil en la historiografía argentina: los estudios migratorios ${ }^{7}$. En esa dirección, fueron fundamentales los trabajos dedicados a reconstruir las experiencias de exiliados y refugiados durante la Segunda Guerra Mundial ${ }^{8}$.

\author{
Asimismo, fueron clave los aportes originados en el \\ terreno de los estudios judíos ${ }^{9}$, cuya revitalización temática
}

además de Wang, Los niños escondidos..., Iván Jablonka, Historia de los abuelos que no tuve (Buenos Aires: Libros del Zorzal, 2015 [Primera edición en francés, 2012]), 1-416 y Omer Bartov, Borrados. Vestigios de la Galitzia judía en la Ucrania actual (Barcelona: Malpaso Ediciones, 2016 [Primera edición en inglés 2007]), 1-249. Para un análisis de los enfoques y análisis más actuales sobre el Holocausto, Iván Jablonka y Annette Wieviorka, comp., Nuevas perspectivas sobre la Shoá (Buenos Aires: Universidad Nacional de Quilmes, 2017), 1-128; en especial, Iván Jablonka, «Nueva memoria para una nueva historia,» en Nuevas perspectivas sobre la Shoá, comps., I. Jablonka y A. Wieviorka (Buenos Aires: Universidad Nacional de Quilmes, 2017), 103-115. De los abundantes libros autobiográficos de sobrevivientes de la Shoá, me apoyo aquí en las obras antes mencionadas de Raschella y Fiszman, La historia que nunca les conté... y Unger, Holocausto... y en el trabajo de Mónica Dawidowicz, Todos mis nombres. Testimonio de una sobreviviente del Holocausto (Buenos Aires: Wolkowicz Editores, 2016), 168, para Argentina. Para otras latitudes, Carry Ulreich, Sueños de paz. Los diarios de una niña judía que sobrevivió al horror nazi. 1941-1949 (Estados Unidos de América: HarperCollins Español, 2018), 1-350 y Simone Veil, Una vida (Buenos Aires: Capital Intelectual, 2010), 280. Especialmente esclarecedora y sugerente fue, sin duda, la lectura de Primo Levi, Si esto es un hombre (Buenos Aires: Ariel, 2015), 224 y Primo Levi y Leonardo de Benedetti, Así fue Auschwitz. Testimonios 1945-1986, ed. Fabio Levi y Domenico Scarpa (Buenos Aires: Editorial Ariel, 2015), 288.

7 Sin ánimo de realizar un listado exhaustivo, me sirvieron especialmente análisis como los de Dora Schwarzstein, "Historia oral y memoria del exilio. Reflexiones sobre los republicanos españoles en la Argentina,» Estudios sobre las Culturas Contemporáneas Vol. III, nº 9 (1990): 149-172, Fernando Devoto, Historia de la inmigración en la Argentina (Buenos Aires: Sudamericana, 2009 [Primera edición 2003]), Bjerg, Historias de la inmigración... y Leonard Senkman, Argentina, la Segunda Guerra Mundial y los refugiados indeseables 1933-1945 (Buenos Aires: Grupo Editor Latinoamericano, 1991) y de Leonard Senkman, «La Argentina neutral de 1940 ante los refugiados españoles y judíos,» Ciclos, Año V, Vol. V, nº 9 (1995): 53- 75.

8 En particular, fueron inspiradores estudios como el de Dora Schwarzstein, «Entre la tierra perdida y la tierra prestada: refugiados judíos y españoles en la Argentina,» en Historia de la vida privada en la Argentina. La Argentina entre multitudes y soledades. De los años treinta a la actualidad, dir. Fernando Devoto y Marta Madero (Buenos Aires: Taurus, 1999), 111-139 y el de Bjerg, El Viaje de los niños.

9 En especial, Malena Chinski, «Un catálogo en memoria del judaísmo polaco. La colección Dos polyche yidntum, Buenos Aires, 1946-1966,» en Marginados y consagrados. Nuevos estudios sobre la vida judía en Argentina, comps. E. Kahan, L. Schenquer, D. Setton y A. Dujovne (Buenos Aires: Lumiere, 2011), 113-238, Daniel Bargman, «Judíos oriundos de Polonia en la Argentina: construcciones identitarias y asociacionismo étnico hasta la segunda postguerra,» en Marginados y consagrados. Nuevos estudios sobre la vida judía en Argentina, comps. E. Kahan, L. Schenquer, D. Setton y A. Dujovne (Buenos Aires: Lumiere, 2011), 165-190, Alejandro Dujovne, Una historia del libro judio. La cultura 
y de enfoques en América Latina ya ha sido señalada por los especialistas $^{10}$, En particular, me sirvieron los estudios sobre las percepciones y análisis del Holocausto en el país $\mathrm{y}^{11}$, más particularmente aún, los exámenes acerca de las experiencias de los judíos en Argentina para honrar la memoria, reconstruir la verdad y atravesar el duelo por los muertos en la Shoá ${ }^{12}$.

Para el caso específico de Tucumán, contamos con el estudio pionero de Isidoro Blumenfeld sobre la historia de la comunidad judía en la provincia ${ }^{13} \mathrm{y}$, más recientemente, con las publicaciones insoslayables de investigadoras como María Esther Silberman de Cywiner, Elisa Cohen de Chervonagura y Denise León, quienes desde el campo de las letras analizaron

judía a través de sus editores, libreros, traductores, imprentas y bibliotecas (Buenos Aires: Siglo XXI, 2014), 304 y Nerina Visacovsky, Argentinos, judios y camaradas. Tras la utopía socialista (Buenos Aires: Editorial Biblos, Colección La Argentina Plural, 2015), 306.

10 Para una puesta al día sobre los estudios judíos en Argentina y Latinoamérica, Daniela Gleizer y Emmanuel Kahan, «Los estudios judíos desde Latinoamérica: temas, perspectivas y diálogos con otras agendas académicas,» Cuadernos Judaicos, $\mathrm{n}^{\circ} 34$ (2017): 1-6, DOI: https://doi.org/10.5354/0718-8749.2017.48001 y Emmanuel Kahan y Alejandro Dujovne, «Los estudios judíos en Argentina y su legitimación en el campo académico: balance y perspectivas,» Cuadernos Judaicos, n 34 (2017), 7-32. DOI: $10.5354 / 0718-8749.2017 .48002$.

11 Algunos aportes centrales fueron, Emmanuel Kahan y Daniel Lvovich, «Los usos del Holocausto en Argentina. Apuntes sobre las apropiaciones y resignificaciones de la memoria del genocidio nazi,» Revista Mexicana de Ciencias Políticas y Sociales Vol. 61, n 228 (2016): 311-336, DOI: https://doi.org/10.1016/S0185-1918(16)300502; Emmanuel Kahan y Malena Chinski, «El Holocausto y la Argentina. Historia, memoria y usos del pasado,» Temas de Nuestra América Vol. 32, n 60 (2016): 1316, DOI: https://doi.org/10.15359/tdna.32-60.8; Celeste Adamoli y Emmanuel Kahan, «El abordaje del Holocausto desde la trama educativa: consideraciones sobre la construcción de una política de educación y memoria,» Aletheia Vol. 7, n 14 (2017): 1-17 y Wanda Wechsler, "La historia de la memoria del Holocausto en Argentina,» Cuadernos Judaicos, $\mathrm{n}^{\circ} 35$ (2018): 261-280, DOI: https://doi.org/10.5354/07188749.2018.52026.

$12 \mathrm{Al}$ respecto, Malena Chinski, «Incertidumbre, búsqueda y duelo: la Shoá desde la perspectiva de los familiares de las víctimas en Argentina,» Temas de Nuestra América Vol. 32, n 60 (2016): 187-2012, DOI: https://doi.org/10.15359/tdna.3260.10 y de Malena Chinski, "La AMIA y el monumento al "mártir desconocido" en el cementerio israelita de la Tablada," en Identidades, memorias y poder cultural en la Argentina (Siglos XIX y XX), comps. María Bjerg e Iván Cherjovsky (Buenos Aires: Universidad Nacional de Quilmes, 2018), 161-198.

13 Isidoro Blumenfeld, Historia de la comunidad Israelita de Tucumán (Tucumán: Sociedad Unión Israelita Tucumana, 1971), 376. 
diversos aspectos de la vida asociativa, sefaradí y ashkenazí, y concedieron un lugar central al rescate de testimonios orales ${ }^{14}$.

Sin embargo, todavía conocemos poco sobre las experiencias de inmigrantes y refugiados judíos en Tucumán durante los tiempos del nacionalsocialismo en Europa. A pesar de su relevancia, la historiografía provincial no ahondó en esta problemática, con lo cual, este trabajo busca avanzar en un campo de estudios poco transitado y de gran vitalidad. Para ello, plantea un examen novedoso de la migración de una refugiada judía basado en el análisis de su diario de viaje, testimonio inédito e inexplorado, sumamente rico para aproximarnos al estudio de las experiencias de quienes pudieron escaparse y, por esa vía, sobrevivir al exterminio del pueblo judío llevado adelante por los nazis.

Antes de comenzar el análisis propiamente dicho, me gustaría señalar que debido a la naturaleza del testimonio analizado, no fue fácil comenzar a escribir la historia de Nechoma; sin embargo, me sentí implicada a hacerlo, consciente de que sus experiencias revelaban dimensiones vinculadas con los recorridos de quienes pudieron salvarse de la Shoá. Paralelamente, el derrotero sufrido por su familia, permitió entrever el desenlace trágico de quienes murieron asesinados en tiempos del nazismo ${ }^{15}$.

14 María Esther Silberman de Cywiner, comp., Asociación Israelita Sefaradí de Beneficencia de Tucumán. Memoria y testimonios de su fundación y evolución (Tucumán: Instituto de Literatura Española (ILE), Facultad Filosofía y Letras, Universidad Nacional de Tucumán, 2006), 126, María Ester Silberman de Cywiner, comp., El patrimonio olvidado, Identidad y memoria (Tucumán: Universidad Nacional de Tucumán, 2012), 208; Elisa Cohen de Chervonagura, La comunidad judía de Tucumán. Hombres y mujeres, historias y discursos, 1910-2010 (Tucumán: Sociedad Unión Israelita Tucumana, Kehilá, 2010), 404, Elisa Cohen de Chervonagura, Eshet Jail, Un contrapunto entre dos mujeres judias (Tucumán: Universidad Nacional de Tucumán, 2015), 500 y Denise León, La vela encendida. Cinco relatos de mujeres que hicieron el Shabat (Tucumán: Instituto Interdisciplinario de Estudios Latinoamericanos, Facultad de Filosofía y Letras, Universidad Nacional de Tucumán, 2002), 162.

15 Un libro inspirador fue el de Jablonka, Historia de los abuelos que no tuve. 


\section{La huida de Polonia a Japón}

Nechoma nació en 1914 en Kobryn, un pueblo de Polonia situado entre Brest-Litovsk y Pinsk. Hacia mediados de la década de 1930 había conocido a su esposo, Mojzesz, oriundo de Wysokie Litewskie (también en Polonia), quien al poco tiempo migró junto con su familia a la Argentina y habitaba en Tucumán. Aunque él esperaba traer después de un tiempo a su esposa, el estallido de la Segunda Guerra Mundial y la atroz persecución a los judíos, que llevaron adelante los nazis y sus colaboradores complicó la migración de ella, quien tuvo que enfrentar numerosos obstáculos para salir de Europa y llegar a la Argentina.

\section{Primera etapa: de Polonia a Lituania}

Cuando el $1^{\circ}$ de septiembre de 1939 comenzó la conquista de Polonia Nechoma vivía todavía con sus padres en Kobryn. «Bombas inesperadas sobre las cabezas y la guerra en todo el camino. El paisito donde tan bien se la pasaba y vivía fue convertido en un campo de sangre, y todo se escapó a donde los pies llevaran ${ }^{16}$. En ese contexto, resumido con estas palabras en su diario de viaje, Nechoma decidió huir de Polonia y emprender su migración a la Argentina. El 24 de diciembre de 1939 (pocos meses después de la ocupación alemana de Polonia) dejó su hogar y de forma ilegal atravesó la frontera hacia Vilna. Según narraba en su manuscrito, llegó allí un 10 de enero y durante unos meses su vida transcurrió de forma relativamente tranquila hasta el ingreso de los rusos en Vilna. Ciertamente, sabemos que las fuerzas soviéticas ocuparon Lituania en junio de 1940 y en agosto de ese año incorporaron Vilna, junto con el resto del país, a la Unión Soviética. Como señala María Bjerg, «la ocupación dio comienzo a una revolución impuesta desde Moscú, pero representada por la prensa soviética como la independencia lituana. Rápidamente

16 «África Marú», Archivo familiar (privado) Nechoma Z., Tucumán-Argentina (AFPN). Nechoma Zaluski, 1 (paginación propia). 
la URSS emprendió una política de sovietización tanto en el plano material como simbólico» ${ }^{17}$.

«Rusia no es democrática, desconoce lo que es tamaña emigración» afirmaba Nechoma mientras se quejaba de la incomprensión de ese país ante las necesidades apremiantes de quienes debían salir de Europa para salvar sus vidas ${ }^{18}$. En efecto, a lo largo de su manuscrito criticó duramente a las autoridades rusas por su maltrato a los migrantes y a sus habitantes, a quienes (según aseguraba) engañaba con falsas promesas y sueños irrealizables.

Son varios los esfuerzos que realizó Nechoma para poder salir de Vilna. En vano trató una y otra vez de obtener la visa necesaria para dejar Europa y ante los reiterados fracasos, se vio obligada a permanecer allí durante un largo periodo. Para solventarse económicamente recurrió a distintas vías. Por un lado, tejió sweaters y, por el otro, trabajó durante un breve tiempo en el Instituto Científico de Vilna, el JIWO, organización dedicada al estudio de los judíos de Europa del Este. Este prestigioso Instituto había sido creado en 1925 y contaba con una sede en Buenos Aires desde 1928. Su fundación en Vilna no era casual, ya que esta ciudad era conocida entonces como la «Jerusalén del Este» por su fértil vida cultural judía. Ciertamente, esta urbe era uno de los centros de irradiación de la cultura judía en Europa, esplendor clausurado con la Segunda Guerra Mundial y la política de terror nazi ${ }^{19}$.

17 «La supresión de la lengua y la cultura lituanas, y la prohibición del uso de la bandera y el himno nacional acompañaron una feroz campaña contra las instituciones no comunistas, entre ellas la iglesia católica». En ese contexto, «la policía perseguía a los disidentes, y las clásicas purgas estalinistas afectaron a miles de ciudadanos que por diferentes razones (sociales, económicas, políticas o culturales), eran considerados como "enemigos de clase". La ejecución o la deportación a Siberia fue el destino de quienes representaban una amenaza a la construcción de la nación socialista", Bjerg, El viaje de los niños, 106-107.

18 AFPN, Zaluski, "África Marú», 2.

19 La centralidad de Vilna en la cultura judía de Europa es señalada, por ejemplo, por Enzo Traverso, El final de la modernidad judia. Historia de un giro conservador (Buenos Aires: Fondo de Cultura Económica, 2014), 44, Visacovsky, Argentinos, judíos y camaradas, 40 y Dujovne, Una historia del libro judio, 50-56. 
Como parte de sus intentos por conseguir los papeles migratorios que le permitieran abandonar Europa y, por ende, salvar su vida, se dirigió al Consulado de Kaunas, donde se suponía podía obtener los documentos requeridos. Tal como señalaba en su diario de viaje, ella era consciente que no podía prolongar más su salida. Sabía que aquellos que no tuvieran una visa japonesa no podrían salir de ninguna manera y estaba al tanto también de la actitud de Moscú, que no mostraba ningún reparo en mandar de regreso a Vilna a todos los que se encontraban en una situación similar.

Para Nechoma, así como para otros judíos en una situación semejante, las esperanzas estaban depositadas en el país nipón, concretamente en obtener una visa de ese país que les permitiera salir de Rusia. En efecto, una de las rutas que siguieron los judíos para escapar del terror nazi fue vía Japón, y para recorrer este camino era necesario conseguir una visa japonesa de tránsito que permitiera dejar Rusia.

Impelida por la necesidad de conseguir dinero para mantenerse y continuar su migración, envió un telegrama a su marido en Argentina, quien le respondió que tuviera paciencia. «Entiendo que en América no se siente cómo arden los pasos en Vilna», se lamentaba ${ }^{20}$. Según se desprende de su narración, se podría suponer que los ecos de la guerra eran lejanos al otro lado del Atlántico; sin embargo, también es posible preguntarse acerca de las posibilidades reales del marido de ayudarla, teniendo en cuenta las restricciones en materia de política migratoria en Argentina, su misma situación como migrante reciente y la falta de recursos, tanto a nivel de vínculos personales, como económicos ${ }^{21}$.

20 AFPN, Zaluski, «África Marú», 2.

21 Los documentos migratorios del marido fueron firmados en el año 1937, con lo cual su migración a la Argentina era muy reciente. Al respecto, podemos mencionar el pasaporte de Mojzesz: "Zaswiadezenie Wojskowe», Archivo familiar (privado) de Nechoma Z., Tucumán- Argentina. También se pueden consultar el certificado de moralidad y el certificado de mendicidad que aseguraba que él nunca había ejercido la mendicidad: «Swiadectwo Moralnosch Dobrych Obyczajow. Certificado Procesal (Moralidad), 12/VIII/1937» y "Swiadectwo o Nieuprawianiu Zebraniny. Certificado de Mendicidad», Archivo familiar (privado) de Nechoma Z., Tucumán-Argentina. Dichos documentos cuentan con el sello que certifica el Permiso de Desembarco, fechado el 17/IX/1937. 
Posteriormente, recurrió a su familia que había quedado en Polonia y como respuesta a su telegrama llegaron su madre y su hermano quienes le trajeron dinero y un poco de equipaje. Lamentablemente, ella tuvo que desprenderse de ese dinero, rublos, ya que le advirtieron que si viajaba con esa moneda caería a mitad de camino. En consecuencia, apeló a otra estrategia. Le pidió dinero a un hombre desconocido, quien le prestó algo de dinero. Además, buscó la ayuda de un amigo, quien también le dio otro tanto ${ }^{22}$, y con eso y con el respaldo del American Jewish Joint Distribution Committee (JOINT) (organismo que databa de 1914 y desempeñó un papel fundamental en la emigración judía de Europa desde el comienzo de la Segunda Guerra Mundial) ${ }^{23}$, pudo finalmente salir de Kaunas el 26 de febrero de ese año de $1941^{24}$. Al otro día, y desde Vilna, pensaba tomar el tren que la llevaría con destino a Vladivostok, donde esperaba obtener la visa japonesa que le permitiría dejar Europa.

\section{Segunda etapa: de Lituania a Rusia}

Con estas ayudas, del JOINT y de quienes le prestaron un poco de dinero, Nechoma pudo finalmente dejar Kaunas el 26 de febrero de 1941. Al otro día, desde Vilna, salió el tren que la llevó a Rusia; entre 12 y 13 días duró el trayecto hasta que llegaron a Vladivostok. Durante ese periodo atravesaron toda Rusia y el espacio fronterizo con Manchuria, Mongolia, Url y

22 En su manuscrito, Nechoma no aclara el tipo de moneda del dinero que consiguió si bien sí cuenta que pudo reunir los 200 dólares que costaba el pasaje en tren. Por otras fuentes, confirmamos que el tren era el Transiberiano Expreso que costaba 200 dólares. «Vuelo y rescate,» United States Holocaust Memorial Museum, acceso el 3 de septiembre de 2019, https://encyclopedia.ushmm.org/content/en/article/flight-andrescue?seriea $=18032$. «Judíos polacos en Lituania: escapar a Japón,» United States Holocaust Memorial Museum, acceso el 3 de setiembre de 2019, https://encyclopedia. ushmm.org/content/en/article/polish-jewish-in-lithuania-escape-to-japan.

23 Michael Beizer, "American Jewish Joint Distribution Committee», The YIVO Encyclopedia of Jews in Eastern Europe, http://www.yivoencyclopedia.org/article. aspx/American_Jewish_Joint_Distribution_Committee.

24 Un análisis de las tareas de ayudas de organizaciones judías internacionales como el JOINT y el World Jewish Congress (Congreso Judío Mundial) para asistir a las víctimas de la Segunda Guerra Mundial en Argentina es el de Ariel Raber, «El Joint, el Congreso Judío, la DAIA y la ayuda a las víctimas de la Shoá en la Argentina,» Coloquio 43 (2017): 1-10, acceso el 21 de junio de 2019, http://congresojudio.org/ coloquio_nota.php?id=296. 
Birobidzhan. El tren se detenía en las grandes estaciones, como Kírov, Sverdlovsk, Omsk, Tomsk, Novosibirsk, Krasnogorsk, Irkutsk y los grandes montes Baikales y el lago Baikal.

En Vladivostok bajó junto con otras 27 personas que también esperaban recibir su visa japonesa. Ella, junto con otras siete personas, obtuvo el documento y no dudó en considerarlo prácticamente un milagro. Al día siguiente, el consulado iba a ser cerrado por completo y los documentos restantes serían devueltos, inclusive con fotos y el dinero pagado, tal como le sucedió a un conocido suyo, afirmaba.

Y por lo tanto, cuando llegó el momento en que pude sentarme en el bote para viajar a Japón, no podía creerlo, cuando cientos de personas permanecían aún en el puerto ruso sin salvoconducto, llenos de dudas sobre qué traería el día siguiente. Y los mismos conocidos que allí permanecían me exigieron con piedad que intentara hacer algo por ellos. Me quedé petrificada, sin poder creer que el destino me había favorecido, que ya estaba por abandonar la frontera del país, del asesino mundial ${ }^{25}$.

Este relato realizó Nechoma al momento de dejar Rusia, un 21 de marzo de 1941. Tal como se reflejó en su testimonio, sus opiniones sobre la Unión Soviética fueron sumamente negativas. De acuerdo con sus propias explicaciones, dichos juicios se basaban en su carácter de testigo, de haber presenciado y sufrido por el estado en el que se encontraban sus habitantes y el maltrato que recibían quienes debían migrar. Además, podemos sugerir que ella participaba de un clima de ideas difundido en la época, donde las aguas se dividían entre quienes depositaban sus esperanzas en el comunismo y aquellos que, por el contrario, se habían desilusionado u observaban los defectos en la aplicación de las políticas socialistas. Según se desprende del examen de su diario, ella fue muy crítica de la Unión Soviética y de sus políticas, lo cual debe leerse, también, a la luz del contexto histórico que le tocó vivir y de sus propias vivencias como joven judía que tuvo que abandonar su patria y su familia para salvarse. De todas maneras, no deja de ser llamativo que depositara en 
Rusia el origen de sus problemas, desdibujando así el papel de Polonia y, en especial, de Alemania, que prácticamente no se mencionaban en su diario.

\section{Tercera etapa: de Rusia a Japón}

La salida de Rusia alegró enormemente a Nechoma pero sus problemas no terminaron allí. El trayecto en barco hacia Japón fue corto y se resolvió bien. Como recordaba en su diario, «los días transcurrieron rápidamente, en total dos días con sus noches. Pero pese a todo no era libre, todavía pertenecía a aquellos que deben atravesar todo» ${ }^{26}$. Con esta expresión que considero sumamente significativa, ella recordaba los nuevos obstáculos que debió enfrentar en su huida. Así, cuando en su viaje hacia Japón llegaron al puerto de Tsuruga todos bajaron pero ella fue demorada junto con otras personas más. Estaba muy preocupada porque era consciente que no tenía todos los documentos en regla ${ }^{27}$. Además, sabía que era necesario controlar en el consulado de Yokohama si ella efectivamente contaba con la visa para continuar, ya que no se permitía ingresar con visas de tránsito como había sido en un comienzo (y a quienes no la tenían se los enviaba de vuelta). Otra de sus preocupaciones era que el cónsul de Yokohama se comportara igual que el cónsul en Kaunas, quien no sólo nunca la recibió sino que además conservó en su poder sus papeles durante siete semanas.

Albergando estos temores y envuelta en estas dudas, recibió la visita de un delegado del Comité Judío de Kobe, el Sr. Gerechter, quien le anunció que el cónsul la llamaba para entregarle la visa. Acompañada por el delegado, fue directo hacia Yokohama y tras 12 horas de viaje, se dirigió al consulado argentino en dicha ciudad. Al respecto, su narración

26 AFPN, Zaluski, «África Marú», 6.

27 Es probable que se refiera al sello que copió de una visa japonesa para poder salir de Lituania y llegar a Vladivostok, tal como sostuvo en la entrevista que le realizó Elisa Cohen de Chervonagura y cuya transcripción me facilitó Diana Mizrahi. En su diario de viaje, Nechoma no mencionó la confección de este documento, aunque es posible inferir que algo había realizado ya que anunciaba la necesidad de engañar a Rusia para poder salir. Así, en su diario, señalaba que gracias a la ocurrencia que tuvo recibió el 29 de enero de 1941 el permiso para salir de Rusia. 
es sumamente reveladora. De acuerdo con su descripción, ella volvió a sentirse como una persona, el cónsul la recibió, le indicó lo que tenía que hacer y se pudieron entender, ya que ambos hablaban inglés. "Ya hacía mucho que no sentía que ella fuera algo», decía, mientras recordaba que en los consulados rusos ni una vez había permanecido demasiado tiempo y no solo ella sino todo el mundo que iba hacia allí. En contraste, ahora el cónsul la recibió, la trató de forma cortés e incluso le convidó un cafecito ${ }^{28}$.

No es una cuestión menor la que mencionaba en su diario de viaje, acerca del comportamiento positivo que tuvo con ella el cónsul en Japón, en contraste con la experiencia desfavorable que había vivido en otras instancias, como el consulado en Kaunas, bajo la ocupación soviética. Específicamente ella reconocía volver a sentirse como una persona debido al buen trato recibido en Japón, en contraste con su vivencia en Lituania dominada por los rusos. En ese contexto, resulta relevante subrayar que, precisamente, la deshumanización era el objetivo que buscaron los nazis con su política contra los judíos. Acaso, ¿no fue justamente este el propósito perseguido por ellos con sus innumerables humillaciones, malos tratos y torturas a los judíos?29.

En el manuscrito de Nechoma eran los rusos los principales verdugos. No obstante, sus sostenidos esfuerzos para poder salir de Europa y escapar de la guerra se situaron en el contexto de la segregación, persecución y, posteriormente, del exterminio, que significó la Shoá. Que ella haya tenido que dejar todo, separarse de sus padres y huir de Polonia formó parte de esta historia dramática que incluyó separaciones familiares, migraciones forzosas y exilios. La trayectoria de

28 AFPN, Zaluski, «África Marú», 6.

29 Son múltiples y diversos los testimonios sobre la deshumanización buscada por los nazis mediante las humillaciones, torturas, privaciones. A modo de ejemplo, resultó esclarecedor el libro biográfico de Veil, Una vida, 35. Por su parte, Primo Levi, sin duda uno de los testimonios más lúcidos de la época, describe las diversas y atroces prácticas desplegadas por los nazis para denigrar a los judíos ante ellos mismos y los demás. Al respecto, Levi, Si esto es un hombre, 79-83, 95-102, 127-141 y 150-163 y Levi y de Benedetti, Así fue Auschwitz..., 22-25, 73-75, 99-103, 109-111, 117-120, 145 y $163-166$. 
Nechoma se inscribe en ese derrotero y, en particular, forma parte de las historias de quienes buscaron, y en su caso consiguieron, migrar y refugiarse en un lugar alejado de la guerra que desangraba a Europa.

Finalmente, el viaje de Nechoma a la Argentina fue posible y en este itinerario una fecha clave fue el 5 de abril de 1941. Ese día recibió la visa y la efeméride quedó registrada en su memoria y en su diario. En consecuencia, todos los documentos migratorios firmados en el Consulado Argentino de Yokohama llevaban esa fecha. Entre estos papeles se encuentra el certificado confeccionado por la Embajada Polaca en Tokio el 29 de marzo de 1941 en el cual constaba que ella era una ciudadana polaca, que el 22 de julio había concluido su trámite de matrimonio ${ }^{30}$. A la constancia de casada se le sumaba el certificado de sanidad emitido el 21 de marzo de 1941 por el Hospital Tokuda de Yokohama y el certificado de finales de marzo de 1941, por el cual la Embajada Polaca en Tokio afirmaba que ella no había cometido ningún delito en los últimos cinco años ${ }^{31}$. Es importante señalar que estos dos últimos documentos, así como su Pasaporte polaco, contenían el Permiso de Desembarco, trámite requerido por las autoridades argentinas de la época ${ }^{32}$. En tal sentido, resulta conveniente subrayar que en el contexto del endurecimiento de las políticas migratorias implementadas desde mediados de los años 1930 en Argentina, aumentaron los requerimientos solicitados

30 «Ambasada Rzeczypospolitej Plskiej W Tokio, Embassy of The Republic of Poland Tokyo, N 729/J/184», Archivo familiar (privado) de Nechoma Z., Tucumán- Argentina. 31 «Yokohama Tokuda Byoin (Hospital «Tokuda» de Yokohama), Certificado de Sanidad» y "Ambasada Rzeczypospolitej Plskiej W Tokio, Embassy of The Republic of Poland Tokyo, N 729/J/184», Archivo familiar (privado) de Nechoma Z., TucumánArgentina.

32 El Permiso de Desembarco, Telegráfico de fecha 22 de Noviembre de 1940, Exp. 86.978/40 se incluyó en los documentos: «Yokohama Tokuda Byoin (Hospital «Tokuda» de Yokohama), Certificado de Sanidad» y "Ambasada Rzeczypospolitej Plskiej W Tokio, Embassy of The Republic of Poland Tokyo, N ${ }^{\circ}$ 729/J/184», Archivo familiar privado de Nechoma Z., Tucumán- Argentina. Asimismo, figuraba en el Pasaporte Polaco de Nechoma: «Paszport Rzeczpospolita Polska, Ser. II. N 290665», Archivo familiar (privado) de Nechoma Z., Tucumán- Argentina. 
para entrar legalmente al país y el permiso de desembarco fue uno de los documentos requeridos entonces ${ }^{33}$.

\section{El viaje de Japón a la Argentina}

Finalmente, y como examinaremos a continuación, Zaluski consiguió abandonar Europa y embarcarse hacia Argentina desde Japón. Su experiencia se inscribió así en un contexto mayor, referido a los refugiados judíos que siguiendo esta ruta lograron salvarse de la guerra y el posterior exterminio nazi.

Ahora sentada ante la ventana de mi pieza que conduce al puerto en el Hotel Bund de Yokohama, me lamento tanto por mis seres queridos y amados que abandoné, ahora que es Erev Pesaj. Entiendo que ellos, allá, no están para preocuparse por preparar la festividad porque ya se destruyó todo [...] Soy de un hogar lleno de tradiciones, y es por eso que me es muy difícil resignarme a la idea de que hoy me encuentro lejos de mis afectos. Ya es el segundo Pesaj lejos de la mesa de mis padres, hace un año en Vilna, hoy en Japón ${ }^{34}$.

Alojada en el Hotel Bund, del cual conservó una fotografía, y mientras esperaba la salida del barco que la llevaría a la Argentina, Nechoma recordaba a su familia que quedó en Polonia y se entristecía al pensar que probablemente no volvería a verlos. El significado de una fecha tan especial para el calendario festivo judío, como era la festividad de Pesaj, agudizaba su nostalgia y tristeza, se sentía lejos de sus padres y temía profundamente no poder reencontrarse con ellos.

33 En julio de 1938 el Presidente Ortiz estableció un decreto que limitaba la entrada de extranjeros al país, al introducir nuevos mecanismos de restricción de la migración que en la práctica ponían en marcha criterios discriminadores de selección de los inmigrantes. «La nueva ley establecía que desde el 1 de octubre los cónsules argentinos en el exterior tenían prohibido el otorgamiento de visas sin la presentación de un "permiso de desembarco". Este solo podía obtenerse a través de un Comité compuesto por representantes de los Ministerios del Interior, Agricultura y Relaciones Exteriores. La intención de la ley era poner en práctica un criterio más discriminado de selección de acuerdo con las nuevas necesidades económicas y culturales del país», sostiene Schwarzstein, "Historia oral y memoria del exilio...», 149. Asimismo, se puede consultar Devoto, Historia de la inmigración..., 390 y Senkman, Argentina, la Segunda Guerra Mundial..., 53- 75. Sobre la política migratoria restrictiva de la época también, Bjerg, Historias de la inmigración...

34 AFPN, Zaluski, «África Marú», 7. 
Un abismo completo hay ahora entre mi familia y yo. Quién sabe si voy a volver a verlos. Éramos tan cercanos y de golpe nos encontramos tan lejos. A veces me debilito tanto, porque mis sentimientos por mi familia y por mi hogar se me juntan. No vivía una vida de ricos, pero mi hogar me dio aquello que está lleno de alma y sentimiento. Soy de un hogar trabajador. Pero aquello con lo que contaba mi hogar era algo que decenas de ricos no se lo daban a sus hijos, aquello que como niños recibimos de mis padres. Y por eso ahora estoy especialmente un poco resquebrajada, anhelante... ${ }^{35}$.

Con estas aflicciones pero al mismo tiempo alentada por la fuerza y el alivio que conllevaba la proximidad de la fecha en que finalmente abandonaría Europa, terminó de resolver todo lo referente a sus papeles y se trasladó a Kobe, de donde saldría su barco con destino a Buenos Aires el 30 de abril de 1941. Tal como contaba en su diario, Vilna, las personas con las que había trabajado en equipo durante su estadía allí y el Consulado de Kaunas volvían a su memoria. Las tristezas se juntaban con las alegrías; todo se mezclaba, decía, al tiempo que evocaba con emoción el día de su partida de Japón ${ }^{36}$.

Fue en un barco de carga, el África Marú, en el cual se embarcó Nechoma, junto con centenares de japoneses que migraban a la Argentina y muy pocos europeos. En primera clase se encontraban un padre que viajaba rumbo a Sudáfrica a reunirse con sus hijos y una mujer, acompañada por su hija, que se dirigía a reunirse con su marido y su padre en el mismo lugar. Por su parte, Nechoma viajaba en tercera clase y allí coincidió con una familia, los Ovjesevich, quienes se trasladaban a Buenos Aires, donde vivían familiares. También en esa sección del barco estaban la señora Przedowa con su niñita de 3 años y medio, quienes iban a rencontrarse con el marido de aquella y una pareja que se dirigía al África. Esos eran los únicos europeos, anotaba en su diario, el resto eran todos japoneses ${ }^{37}$.

35 AFPN, Zaluski, «África Marú», 8.

36 AFPN, Zaluski, «África Marú», 8.

37 AFPN, Zaluski, «África Marú», 9. 
Diana Wang, en su libro sobre los niños que se salvaron del Holocausto, reconstruye y analiza la historia de Dina Ovjesevich, quien siendo una niña de siete años viajó con su familia en el África Marú. Leer el testimonio de Dina O. y comprobar la coincidencia entre la información que ella aporta y los datos revelados en el diario de Nechoma fue realmente conmovedor $^{38}$. A través de la información proporcionada por ambas narraciones, puede corroborarse la exactitud y la veracidad de los relatos. De esta forma, no eran vanas las palabras de Nechoma cuando decía: «si alguien leyera mi diario lo entendería muy fácil, porque todo ocurrió tal como fue escrito» ${ }^{39}$.

Dina y Nechoma coincidieron en el barco, viajaron en el África Marú y arribaron en Buenos Aires al promediar 1941, aunque Dina, a diferencia de Nechoma, iba en compañía de su familia y obtuvo la visa en el Consulado japonés en Kaunas en julio de $1940^{40}$. Como ellas, otras personas pudieron salvarse de la Shoá al abandonar Europa vía Japón. Por ejemplo, entre las historias resguardadas por el Museo del Holocausto en Estados Unidos se encuentra la de Ruth Berkowicz Segal, quien pudo escaparse de Polonia atravesando la Unión Soviética en el Transiberiano hasta Vladivostok, luego fue a Kobe y desde allí viajó junto con su padre en barco hacia los Estados Unidos. Por su parte Lucille Szepsenwol Camhil, junto con su madre y hermana, escaparon de Volozhin, que estaba en la zona de Polonia ocupada por los soviéticos, yendo

38 Wang, Los niños escondidos...121.

39 AFPN, Zaluski, «África Marú», 9.

40 A partir de entonces, «el plan de huida consistía en atravesar toda la Unión Soviética hasta Japón y allí embarcarse hacia algún destino. Había que conseguir visados de tránsito y la aprobación soviética dependía de una previa aprobación japonesa», señala Wang, Los niños escondidos... 149. Una consideración semejante habíamos mencionado ya en este trabajo, al referirnos a la certeza de Nechoma acerca de la necesidad de conseguir la visa japonesa para poder salir de Rusia. Sobre la importancia de Kaunas (antes llamada Kovno) para la vida cultural judía y el alcance de la destrucción de la población judía y sus manifestaciones durante la Shoá, se puede ver por ejemplo, «Mundo judío virtual: Kovno (Kaunas), Lituania, por Jono David», Jewish Virtual Library, https://www.jewishvirtuallibrary.org/kovno-kaunaslithuania-jewish-history-tour. 
primero a Vilna y desde allí viajaron en el Transiberiano hacia Japón, donde se embarcaron para Estados Unidos ${ }^{41}$.

Quise mencionar estos testimonios porque revelan una de las rutas a través de las cuales los judíos pudieron salir de Europa: el escape vía Japón. En general, los destinos posibles eran Palestina, Estados Unidos y Sudamérica. En el caso del África Marú, la ruta que siguió fue la siguiente. Salió el 30 de abril desde Kobe; primero se detuvo en el Puerto de Singapur, donde bajaron los pasajeros y recorrieron la ciudad. Según Nechoma, era una ciudad muy bonita, bien construida. Había judíos pero no estaban organizados en comunidad, afirmaba. Después, el barco pasó por Sobang, donde ella sintió que era completamente hechizada por su belleza. Contaba en su diario que le daban ganas de subir a una montañita, pero los vigilaban y no podían $i^{42}$. Entonces, pensaba con amargura cuándo llegaría el fin para la competencia entre Estados a través del método de la guerra. Nuevamente recordaba a sus padres y a su hogar. Volvía a sentir esas aflicciones, mientras de a poco abandonaban las pequeñas islas, vinculadas unas a las otras, Sumatra, Borneo y Java, y el barco se internaba en el Océano Índico.

Una vez que pudo mejorar un poco su situación en el barco, ya que consiguió trasladarse junto con su amiga, la Sra. Przedowska, a otro camarote (donde podían estar un poco más cómodas) aprovechó el tiempo para mejorar su inglés y comenzó a aprender un poco de castellano. Según anotaba en su manuscrito, el viaje era monótono pero cuando llegaba el shabat, la noche del viernes, sentía una añoranza extraordinaria. Recordaba la veraniega noche del viernes en su pueblo, en su hogar. Evocaba el viernes en la tarde, cuando su padre solía cantar zmires (los cantos sabáticos) con todos los hijos alrededor de la mesa. Entonces volvían sus pensamientos tristes. Recordaba cómo ese mundo cambió dramáticamente, cómo se perdió para siempre. «Lo primero

41 «Testimonios», United States Holocaust Memorial Museum, acceso el 1 de Julio de 2019, https://encyclopedia.ushmm.org/content/es/oral-history/.

42 AFPN, Zaluski, "África Marú», 11. 
fue cuando mi hermano marchó al ejército en noviembre de 1938. Luego en 1939 el estallido de la guerra nos destruyó por completo. Me fui del hogar y todo desapareció. Los miserables, brutales caprichos de Estados que destruyeron todo, y cuando se les volvió aburrido bañarse en oro y buena vida, empezaron a esclavizar al ciudadano de a pie. Un caos necesitó volverse el mundo entero», afirmaba ${ }^{43}$.

El 30 de mayo llegaron a Lorenzo Marques. Pudieron bajar a la ciudad lo cual fue una alegría tras cuatro semanas en el barco. Al recorrer la ciudad se encontraron con un grupo de personas, otros judíos venidos de Francia y Bélgica a través de España que habían bajado allí porque temporalmente no se podía continuar. A través de las conversaciones que tuvieron con ellos, se enteraron de las noticias de la guerra. «Porque estando en el barco no teníamos posibilidades de enterarnos de nada", decía. En cambio, al encontrarse con ellos supieron, por ejemplo, que Alemania amenazaba a los Balcanes «y pronto empieza a temblar la tierra en la que nos encontramos», anotaba en su manuscrito. Asimismo, supieron que el barco no podría continuar y que debían quedarse allí tal vez 8 o 10 días. No había noticias acerca de si podrían ingresar en Durban, ya que este era un puerto inglés y no se sabía cómo continuaría la guerra ${ }^{44}$.

Finalmente partieron a Durban y luego de tres días de permanecer a mar abierto, pues no autorizaban a ingresar al puerto, consiguieron el permiso necesario para entrar. Desde allí, partieron el 21 de junio a Cape Town y a los ocho días de viaje supieron que ya no irían a Buenos Aires sino a Brasil. En ese trayecto, se enteró de tristes y amargas novedades sobre la marcha del conflicto bélico y las luchas políticas. Alemania le había declarado la guerra a Rusia y su tristeza fue cuando supo que Alemania había tomado Vilna, Bialystok, Brest-Litovsk; Lemberg, Minsk, etc. ¿Qué van a hacer ahora 
mis padres? se preguntaba; «no se es millonario», decía en su escrito $^{45}$.

El 3 de julio el África Marú entró al puerto de Río de Janeiro y, finalmente, tras pasar por el puerto de Santos (donde no se los dejó descender) se dirigieron a Buenos Aires, a donde llegaron el 9 de julio de ese año 1941. El recuerdo y las vivencias de ese día quedaron registradas en su memoria y plasmadas en su diario de viaje; sin embargo, como ella misma reconocía «no todo puede ser retratado. Porque sentimientos, inquietudes, son imposibles de expresar con palabras...Eran experiencias internas fuertes, que se atraviesan una vez en la vida». ${ }^{46}$

\section{De Buenos Aires a Tucumán}

Nechoma estuvo dos días en Buenos Aires. Allí, se rencontró con amigas de Polonia y con su esposo, quien se ocupó de realizar los trámites necesarios para continuar el viaje hacia Tucumán. Era un 12 de julio de 1941 cuando llegó a la provincia y fue recibida por la familia de su marido, quienes se mostraban sinceramente interesados en su viaje y sobre todo en sus descripciones sobre la Unión Soviética. No obstante, ella no quiso entrar en discusiones sobre este tema, porque dudaba de compartir sus opiniones con personas que no habían experimentado lo que ella vivió. Y mientras comenzaba su nueva vida como "una ciudadana tucumana», según sus propias palabras, no perdía las esperanzas de volver a ver a sus padres y a su familia ${ }^{47}$.

El 9 de julio de 1942, cuando había transcurrido exactamente un año de su llegada a la Argentina, ella se alegraba de estar en el país, donde se podía construir una vida muy bella, más tranquila y pacífica, similar a la experimentada alguna vez en Europa, antes de la guerra; sin embargo, se

45 AFPN, Zaluski, «África Marú», 17.

46 AFPN, Zaluski, «África Marú», 19-20.

47 AFPN, Zaluski, «África Marú», 22. 
lamentaba profundamente por la separación y la situación de su familia.

Escribo ahora estas palabras con mucho dolor. Antes, cuando escribía, estaba sola, viajando, sin saber a dónde me llevaría el mañana, pero ahora que me encuentro en mi hogar, organizada, comiendo y bebiendo todo lo que hay acá, cuando yo misma tengo que descartar cosas, con las que alegraría mi hogar, y aguardo, me es muy doloroso. Cuando sin embargo me encuentro tranquila, reconfortada, pero ni una palabra de mis padres, ni de los chicos, tengo el corazón lleno de dolor. Lo que se vive se disfruta, pero por dentro con mucho dolor. Me escapé sola, una de mi generación que se salvó ${ }^{48}$.

Esta angustia, combinada con la culpa y el desconcierto volvían una y otra vez a su mente. Las noticias sobre la guerra se difundían y para finales de 1942 sus esperanzas eran cada vez menores.

Es muy triste vivir cuando allá se derrama la propia sangre; cuando allá, al otro lado del Atlántico, lo más querido de la propia sangre y carne es aniquilada. Es muy duro. Y en tiempos así no se puede hablar, el corazón se comprime con tenazas y ni siquiera una lágrima logra salir ${ }^{49}$.

Cada vez más, cobraba fuerza la certeza de haber sido la única que se salvó de su familia. Con este conocimiento, el peso también crecía.

Yo misma me salvé de todos los tormentos, pero realmente me duele el corazón por mis padres, que hasta ahora tan poco disfrutaron de sus vidas, y por mis hermanitas y hermanitos, que hasta ahora no disfrutaron nada en sus vidas, y todavía no saben ni siquiera qué es vivir. Entonces, imagínense ${ }^{50}$.

Si cuando ella escribía estas líneas aún conservaba esperanzas de ver a su familia, el final de la guerra y, sobre todo, las noticias acerca de la magnitud del Holocausto terminaron por disipar toda ilusión. En ese sentido, es importante señalar que su diario de viaje concluye hacia finales de 1946, cuando

48 AFPN, Zaluski, "África Marú», 23. 49 AFPN, Zaluski, «África Marú», 25. 50 AFPN, Zaluski, «África Marú», 25. 
ya habían pasado entre cuatro y cinco años de su llegada a la Argentina. Para esa fecha, el anhelo de reencontrarse con su familia que había quedado en Polonia se desdibujó, en consonancia con la difusión de la información sobre el impacto de la guerra y el alcance de la destrucción a la población judía en Europa ${ }^{51}$.

En ese contexto, podemos interpretar sus sentimientos frente a la lectura del diario del 20 de noviembre de $1946 \mathrm{y}$, en especial, su experiencia demoledora (tal como ella misma la describía) cuando se encontró con la noticia puntual de su ciudad natal, donde vivió 24 años. "Cómo se condujo a la muerte a los judíos de Kobryn», decía el artículo. Se le pusieron los pelos de punta, afirmaba Nechoma. Los sentimientos que le produjo tal información eran inconmensurables. «iAy! Cómo se puede leer eso hasta el final y quedarse en el lugar. Cómo se lo puede comprender solo con palabras», exclamaba con pesar en su diario ${ }^{52}$.

Al dolor que sentía por sus seres queridos asesinados, a la nostalgia y la tristeza que experimentaba por su pueblito, como decía ella, el lugar donde habían nacido todos sus afectos, se le sumaba la angustia que conllevaba la falta de una lápida, de una tumba en donde llorar a los muertos. Su dolor crecía, además, ante la certeza de saber que entre los muertos se encontraban tantos niños, tantos jóvenes, como sus hermanos. Los nombraba, recordaba algunas de sus historias antes de que ella saliera de Polonia. Se lamentaba, se entristecía.

"Yo, una salvada», decía Nechoma y evocaba también cuando sus padres le dijeron en diciembre de 1939 «andá,

$51 \mathrm{Al}$ respecto, fue sugerente el artículo de Chinski, "Incertidumbre, búsqueda y duelo...», 187-202, en donde la autora analiza, a través de diversos testimonios, la dificultosa tarea de los judíos que ya vivían en Argentina por averiguar si se encontraban con vida sus parientes que habían permanecido en Europa durante la Shoá. Entre otros aspectos, examina las expresiones de dolor y pesar cuando ellos se enteraban de las tremendas muertes que habían sufrido sus parientes más cercanos, asesinados en campos, muertos en los guetos o tras las deportaciones. También, explora las manifestaciones de esperanza que antes de conocer acerca de sus muertes, alimentaban aquellos hombres y mujeres judíos en Argentina por reencontrarse con sus familiares.

52 AFPN, Zaluski, «África Marú», 28. 
sálvate. Acá no va a estar bueno. Te vas. No hay nada que hacer, que no te lleve el destino» ${ }^{53}$. Ella dudó, ¿cómo se abandona a los padres?, se preguntaba. ¿Cómo se deja a los padres que tanto hicieron por ella, en especial teniendo en cuenta todos los esfuerzos que realizaron por darle educación, cuidados, sin ser ellos profesionales, sin tener recursos suficientes? Mencionaba en su diario acerca de la educación que había recibido, explicaba cómo su familia había conseguido decoro en Kobryn, al enviar a sus hijos a estudiar y terminar los estudios; sin embargo, se lamentaba profundamente de cómo a pesar de haber aprendido en las mejores escuelas y conservar tantos recuerdos de su hogar, tuvo que abandonar todo y partir a la lejana Argentina. Sufría al no tener cerca de ella a algún miembro de su familia, un hermano por ejemplo que pudiera ayudarla a disminuir su dolor. Evocaba nuevamente lo sucedido a sus padres y sufría. "Personas jóvenes, en los cincuenta, cuando empieza para la gente de bien la vida misma. Murieron. ¿Por qué? ¿Para quién? Vidas jóvenes extinguidas eternamente. Todo fue exterminado. Borrado» ${ }^{54}$.

\section{La participación de Nechoma en la vida asociativa judía local: filantropía, idish y sionismo}

En esta breve sección, y si bien esto deberá ser retomado en un trabajo futuro, me gustaría sugerir que sus opiniones críticas sobre Rusia y, en contraste, su beneplácito ante la actitud de países como Japón, en especial sobre el papel de las autoridades consulares, convivieron con el inconmensurable dolor ante la pérdida de su familia en la Shoá y de su vida en Polonia. Estos sentimientos y posturas formaron parte de sus experiencias de migración y exilio y junto con sus aprendizajes y vida familiar en Polonia, sumadas a sus nuevas vivencias en Argentina, gravitaron en la trayectoria de Nechoma, permitiéndole construirse como una mujer luchadora y activa en la vida de la comunidad judía local, particularmente en los terrenos relacionados con la enseñanza del idish y el sionismo. En su recorrido biográfico, además, se revelaron la solidaridad 
y preocupación por el otro, atributos que recuperaban las ayudas recibidas en su travesía migratoria, al tiempo que evidenciaban su empatía y preocupación por el prójimo. A modo de ejemplo, podemos señalar la actividad que desarrolló junto con otras mujeres, con quienes se reunía para coser ropa y entregarla a las personas que las necesitaban en la sociedad tucumana ${ }^{55}$.

A partir de la información recabada en diversas fuentes, tiene sentido proponer que esta tarea fue realizada por Nechoma en el marco de su participación en el mundo asociativo judío de Tucumán. Muestra de lo anterior fue su intervención en el grupo de mujeres pioneras denominado Comité de Mujeres Amigas de la Histadrut, asociación que se había fundado el 30 de agosto de 1945, en el local social de la Liga Pro Palestina Obrera. Esta organización femenina trabajó activamente en distintas esferas vinculadas con la educación judía, la cultura y el sionismo, y mantuvo estrechas relaciones con la sede de Buenos Aires, creada en 1944. Por ejemplo, el Comité de Mujeres Amigas de la Histadrut estableció un taller de costura en el cual las mujeres se dedicaban a confeccionar ropa de vestir, toallas y manteles. Por otro lado, esta asociación impulsó también conferencias, funciones de cine, conciertos, recitales y otras reuniones en el marco de la celebración de las fiestas judías ${ }^{56}$.

Otro vértice de la participación de Nechoma en el terreno asociativo se manifestó en el ámbito del idish, específicamente a través de su labor como maestra en la escuela de la comunidad judía tucumana a comienzos de la década de $1960^{57}$. Además, fue corresponsal del Naie Zait (Nueva Era), diario escrito en idish y publicado en Buenos Aires ${ }^{58}$.

55 Diana Mizrahi (arquitecta), entrevista por Vanesa Teitelbaum, 28 de junio de 2018.

56 Blumenfeld, Historia de la comunidad, 222-223.

57 Silvia Pniewski (Profesora) y Diana Mizrahi (arquitecta), entrevistas por Vanesa Teitelbaum, junio y julio de 2018.

58 Blumenfeld, Historia de la comunidad, 326-327. 
Aparte de sus labores en la educación, el periodismo y la filantropía, Nechoma intervino activamente en los órganos de dirección de la comunidad judía, al participar en la Delegación de Asociaciones Israelitas Argentinas (DAIA) y en comisiones directivas de una institución nodal del asociacionismo judío tucumano, la Sociedad Unión Israelita Tucumana (conocida como Kehilá ashkenazi). Sobre esto último, es relevante apuntar que fue una de las pocas mujeres que integró instancias directivas en dicha asociación ${ }^{59}$, lo cual constituye una de las evidencias de la respetabilidad y el reconocimiento que alcanzó en la comunidad. Dentro de sus tareas asociativas en la Kehilá destacaron aquellas que demostraban su preocupación por el sionismo, tal como se reveló, por ejemplo, en su participación en una actividad impulsada por esta asociación para promover sus principios: el Vaadat-Aliá, organismo local de intercambio argentinoisraelí creado en 1964, y posteriormente conformado como una filial de la Organización Sionista Argentina ${ }^{60}$.

Mediante estas varias y diversas incursiones en la vida comunitaria local, Nechoma cumplía su anhelo de contar con una vida social. En efecto, en julio de 1942, cuando llevaba un año viviendo en Tucumán, expresó claramente esta aspiración en su diario, donde comentaba, además, acerca de sus visitas a lugares cercanos, su encuentro con personas que ella consideraba interesantes y, principalmente, su acercamiento al castellano. De su esfuerzo por aprender el idioma y de la importancia otorgada a esta labor, dan cuenta sus agendas personales en las cuales dedicó numerosas páginas a transcribir poemas y letras de canciones que luego traducía desde el polaco y el idish al castellano. La conocida zamba «Luna Tucumana», la más representativa de la provincia en la cual ella vivió, es precisamente una de las canciones que se encuentran en estas agendas ${ }^{61}$.

59 Blumenfeld, Historia de la comunidad, 300.

60 Blumenfeld, Historia de la comunidad, 300.

61 «Agenda», Archivo familiar (privado) de Nehoma Z., Tucumán-Argentina. 


\section{Conclusiones}

A través de la historia de Nechoma Zaluski buscamos en este trabajo avanzar en el análisis del movimiento migratorio derivado de la Segunda Guerra Mundial y las acciones de violencia implementadas por los nazis. En particular, el estudio intentó mostrar una de las rutas seguidas por los refugiados judíos: el escape vía Japón. De acuerdo a nuestro examen de las fuentes, podemos proponer que el itinerario recorrido y la salida de Europa a mediados de 1941 fueron decisivas, ya que a finales de ese año, los esfuerzos por migrar hubieran sido prácticamente imposibles, teniendo en cuenta los episodios que jalonaron la política de segregación, persecución y exterminio del nazismo ${ }^{62}$.

Al escapar durante los primeros años de la contienda bélica y migrar a la Argentina, Zaluski se convirtió en una refugiada y sobreviviente de la Shoá. Al mismo tiempo, fue familiar directo de las víctimas de la catástrofe. En esa tónica, su manuscrito trasluce la preocupación y angustia por los familiares que permanecieron en Europa durante la guerra y el avance del terror nazi. Más adelante, estos sentimientos de dolor se incrementaron cuando se conoció el alcance del exterminio nazi. En ese contexto, las aflicciones se agravaron y afloraron el peso y la culpa al saber que era la única que se había salvado de su familia ${ }^{63}$.

$62 \mathrm{Al}$ respecto, interesa recuperar la distinción realizada por Wang acerca de las dos etapas en que huyeron los judíos de Europa. Según esta autora, «la huida de los judíos durante la Segunda Guerra Mundial se dio en dos momentos bien diferenciados: antes del ingreso a los guetos, o sea entre 1939 y 1940, y otro momento, muy posterior, luego de 1943. Los que lograron escapar en el primer momento estaban más enteros, no solo porque en general los grupos familiares continuaban unidos, sino también porque aún tenían recursos y mejores condiciones físicas y anímicas. Los que huyeron luego de 1943, de los guetos o los campos de concentración, ya eran seres exhaustos, con las familias fragmentadas y con recursos mucho menores. Su huida correspondió al momento de la acción más desenfrenada de la "solución final"». Wang, Los niños escondidos..., 111.

63 Por ejemplo, Schwarzstein, en su trabajo sobre los refugiados judíos y los exiliados españoles, sostiene que una de las características centrales en la construcción de sus identidades fue «la culpa por la suerte de los que quedaron, que en el caso de los judíos sería aún peor cuando se revelaran en toda su dimensión las atrocidades del régimen nazi», Schwarzstein, «Entre la tierra perdida y la tierra prestada»,116-117. 
Como otros sobrevivientes, Nechoma encauzó sus sufrimientos hacia una tarea esencial: contar lo que pasó y, por esa vía, tratar de evitar que algo semejante pudiera volver a ocurrir. ${ }^{64}$ Considero que la escritura de su diario puede ser situada en ese horizonte destinado a transformar el pasado en proyectos dirigidos a conservar la paz y prevenir en el futuro cualquier genocidio. Por otro lado, Zaluski participó en actividades dirigidas a difundir el idish y el sionismo y, paralelamente, ocupó lugares destacados en instituciones de ayuda mutua y filantropía judías destinadas a fomentar la asistencia a los más necesitados. De esta forma, su trayectoria compartió rasgos comunes con otros refugiados y sobrevivientes judíos del nazismo, quienes fortalecidos por sus experiencias, canalizaron sus vivencias en tareas educativas y de transmisión de memoria, al tiempo que transitaron los senderos del asociacionismo judío.

Otro vértice que se desprende del análisis de su diario fue el descontento y el enojo que experimentó frente a determinadas políticas, como las de Rusia y su trato hacia los migrantes. En contraposición, el escrito expresó el agradecimiento por los apoyos recibidos durante su travesía migratoria y su regocijo al sentirse nuevamente tratada como persona, vivencia experimentada en las oficinas migratorias de Japón. Con lo cual, merece destacarse también la singularidad del testimonio analizado, el cual focalizaba en Rusia las críticas, prácticamente no mencionaba el papel de Polonia y, recién hacia el final de su diario, se refería al de Alemania. Los procesos concernientes a la Segunda Guerra Mundial y a la

\footnotetext{
64 En esa tónica, resultaron valiosos análisis como los de Primo Levi, quien tras sostener que «la persecución nazi fue de una ferocidad sin parangón», Levi y de Benedetti, Así fue Auschwitz... 164 describe, ejemplifica y denuncia esta política de barbarie y terror de la cual él mismo fue un sobreviviente. Tal como afirma Levi, los innumerables desprecios, humillaciones y violencias infligidos por los nazis a los judíos produjeron destrucción, letargo y en definitiva redujeron la humanidad en las víctimas, quienes debían luchar a diario con el hambre, el frío y la abominable política que imperaba en los campos de concentración (abundantes ejemplos de la crueldad y la barbarie que caracterizó al nazismo en Levi y de Benedetti, Así fue Auschwitz... y Levi, Si esto es un hombre, 77-189. Frente a semejante horror, los sobrevivientes tenían un deber: contar lo que pasó, Levi y de Benedetti, Así fue Auschwitz, 145 y166 y Levi, Si esto es un hombre, 7-8.
} 
política soviética posiblemente expliquen estas vivencias, en particular el malestar y repudio hacia el comunismo, aspectos que deberán ser retomados en un trabajo futuro.

Por último, quisiera subrayar la relevancia de investigar los sentimientos y las experiencias de refugiados judíos y sobrevivientes de la Shoá, entendida como «un acontecimiento universal que trasciende a todas las naciones y concierne a todos los seres humanos» ${ }^{65}$. Más aún, sugiero, esta importancia se incrementa para el caso de Tucumán, espacio provincial que carece de este tipo de aproximaciones historiográficas.

\section{Fuentes primarias}

Archivo familiar (privado) Nechoma Z., Tucumán-Argentina (AFPN). Zaluski, Nechoma. «África Marú».

Archivo familiar (privado) de Nechoma Z., Tucumán- Argentina. «Zaswiadezenie Wojskowe».

Archivo familiar (privado) de Nechoma Z., Tucumán-Argentina. «Swiadectwo Moralnosch Dobrych Obyczajow. Certificado Procesal (Moralidad), 12/VIII/1937».

Archivo familiar (privado) de Nechoma Z., Tucumán-Argentina. «Swiadectwo o Nieuprawianiu Zebraniny. Certificado de Mendicidad».

Archivo familiar (privado) de Nechoma Z., Tucumán- Argentina. «Ambasada Rzeczypospolitej Plskiej W Tokio, Embassy of The Republic of Poland Tokyo, $N^{\circ} 729 / \mathrm{J} / 184 »$

65 En esa dirección, me hago eco de las palabras de especialistas en el tema, como Jablonka, quien plantea el primado de la investigación para nutrir la memoria de la Shoá. Además, propone «la celebración de la vida (producir una biografía antes que una necrología) (...), el reconocimiento de la especificidad Shoá (se trata de un acontecimiento único, no declinable); la universalización de la memoria (los genocidios sobrepasan a sus víctimas) y la renovación permanente de los modos de recuerdo y de transmisión contra la idea fija de un deber de memoria)», en Iván Jablonka, «Nueva memoria para una nueva historia,» en Nuevas perspectivas sobre la Shoá, comps. I. Jablonka y A. Wieviorka (Buenos Aires: Universidad Nacional de Quilmes, 2017), 103-115. 
Archivo familiar (privado) de Nechoma Z., Tucumán- Argentina. «Yokohama Tokuda Byoin (Hospital «Tokuda» de Yokohama), Certificado de Sanidad».

Archivo familiar (privado) de Nechoma Z., Tucumán- Argentina. «Paszport Rzeczpospolita Polska, Ser. II. N 290665».

United States Holocaust Memorial Museum, «Testimonios». Acceso el 1 de julio de 2019, https://encyclopedia.ushmm.org/content/ es/oral-history/.

United States Holocaust Memorial Museum. «Vuelo y rescate». Acceso el 3 de septiembre de 2019, https://encyclopedia.ushmm.org/ content/en/article/flight-and-rescue?seriea=18032.

United States Holocaust Memorial Museum. «Judíos polacos en Lituania: escapar a Japón». Acceso el 3 de setiembre de 2019, https://encyclopedia.ushmm.org/content/en/article/polishjewish-in-lithuania-escape-to-japan.

\section{Entrevistas}

Mizrahi, Diana. Entrevista por Vanesa Teitelbaum. 28 de junio de 2018.

Pniewski, Silvia. Entrevistas por Vanesa Teitelbaum. Junio y julio de 2018.

\section{Bibliografía}

Adamoli, Celeste, y Emmanuel Kahan. «El abordaje del Holocausto desde la trama educativa: consideraciones sobre la construcción de una política de educación y memoria.» Aletheia Vol. 7, n 14 (2017): 1-17. Acceso el 18 de mayo de 2019. http://www. memoria.fahce.unlp.edu.ar/art_revistas/pr.7892/pr.7892.pdf.

Bargman, Daniel. «Judíos oriundos de Polonia en la Argentina: construcciones identitarias y asociacionismo étnico hasta la segunda postguerra.» En Marginados y consagrados. Nuevos estudios sobre la vida judía en Argentina. Compilado por E. Kahan, L. Schenquer, D. Setton y A. Dujovne, 165-190. Buenos Aires: Lumiere, 2011, 
Bartov, Omer. Borrados. Vestigios de la Galitzia judía en la Ucrania actual. Barcelona: Malpaso Ediciones, 2016 [Primera edición en inglés 2007].

Beizer, Michael. «American Jewish Joint Distribution Committee», The YIVO Encyclopedia of Jews in Eastern Europe, http:// www.yivoencyclopedia.org/article.aspx/American_Jewish_ Joint_Distribution_Committee.

Bjerg, María. Historias de la inmigración en la Argentina. Buenos Aires: Edhasa, 2009.

Bjerg, María. El Viaje de los niños. Inmigración, infancia y memoria en la Argentina de la Segunda Posguerra. Buenos Aires: Edhasa, 2012.

Blumenfeld, Isidoro. Historia de la comunidad Israelita de Tucumán. Tucumán: Sociedad Unión Israelita Tucumana, 1971.

Chinski, Malena. «Un catálogo en memoria del judaísmo polaco. La colección Dos polyche yidntum, Buenos Aires, 1946-1966.» En Marginados y consagrados. Nuevos estudios sobre la vida judia en Argentina. Compilado por E. Kahan, L. Schenquer, D. Setton y A. Dujovne, 113-238. Buenos Aires: Lumiere, 2011.

. "Incertidumbre, búsqueda y duelo: la Shoá desde la perspectiva de los familiares de las víctimas en Argentina.» Temas de Nuestra América Vol. 32, n 60 (2016): 187-202. DOI: https://doi.org/10.15359/tdna.32-60.10.

«La AMIA y el monumento al "mártir desconocido" en el cementerio israelita de la Tablada.» En Identidades, memorias y poder cultural en la Argentina (Siglos XIX y XX), compilado por María Bjerg e Iván Cherjovsky, 161198. Buenos Aires: Universidad Nacional de Quilmes, 2018.

Cohen de Chervonagura, Elisa. La comunidad judía de Tucumán. Hombres y mujeres, historias y discursos, 1910-2010. Tucumán: Sociedad Unión Israelita Tucumana, Kehilá, 2010. . Eshet Jail, Un contrapunto entre dos mujeres judías. Tucumán: Universidad Nacional de Tucumán, 2015. 
Dawidowicz, Mónica. Todos mis nombres. Testimonio de una sobreviviente del Holocausto. Buenos Aires: Wolkowicz Editores, 2016.

Devoto, Fernando. Historia de la inmigración en la Argentina. Buenos Aires: Sudamericana, 2009 [Primera edición 2003].

Dujovne, Alejandro. Una historia del libro judio. La cultura judía a través de sus editores, libreros, traductores, imprentas y bibliotecas. Buenos Aires: Siglo XXI, 2014.

Gleizer, Daniel, y Emmanuel Kahan. «Los estudios judíos desde Latinoamérica: temas, perspectivas y diálogos con otras agendas académicas.» Cuadernos Judaicos, nº 34 (2017): 1-6. DOI: https://doi.org/10.5354/0718-8749.2017.48001

Jablonka, Iván. Historia de los abuelos que no tuve. Buenos Aires: Libros del Zorzal, 2015 [Primera edición en francés, 2012].

. «Nueva memoria para una nueva historia.» En Nuevas perspectivas sobre la Shoá. Compilado por I. Jablonka y A. Wieviorka, 103-115. Buenos Aires: Universidad Nacional de Quilmes, 2017.

Jablonka, Iván, y Annette Wieviorka, comp. Nuevas perspectivas sobre la Shoá. Buenos Aires: Universidad Nacional de Quilmes, 2017.

Kahan, Emmanuel, y Alejandro Dujovne. «Los estudios judíos en Argentina y su legitimación en el campo académico: balance y perspectivas.» Cuadernos Judaicos, $\mathrm{n}^{\circ} 34$ (2017): 7-32. DOI: $10.5354 / 0718-8749.2017 .48002$.

Kahan, Emmanuel, y Daniel Lvovich. «Los usos del Holocausto en Argentina. Apuntes sobre las apropiaciones y resignificaciones de la memoria del genocidio nazi.» Revista Mexicana de Ciencias Políticas y Sociales Vol. 61, n 228 (2016): 311-336. DOI: http://dx.doi.org/10.1016/S0185-1918(16)30050-2.

Kahan, Emmanuel, y Malena Chinski. «El Holocausto y la Argentina. Historia, memoria y usos del pasado.» Temas de Nuestra América Vol. 32, nº 60 (2016): 13-16. Acceso el 21 de mayo de 2019. https://www.revistas.una.ac.cr/index.php/tdna/ article/view/8997. DOI: https://doi.org/10.15359/tdna.32-60.8. 
Levi, Primo. Si esto es un hombre. Buenos Aires: Ariel, 2015.

Levi, Primo, y Leonardo de Benedetti. Así fue Auschwitz. Testimonios 1945-1986, editado por Fabio Levi y Domenico Scarpa. Buenos Aires: Editorial Ariel, 2015.

León, Denise. La vela encendida. Cinco relatos de mujeres que hicieron el Shabat. Tucumán: Instituto Interdisciplinario de Estudios Latinoamericanos, Facultad de Filosofía y Letras, Universidad Nacional de Tucumán, 2002.

Raber, Ariel. «El Joint, el Congreso Judío, la DAIA y la ayuda a las víctimas de la Shoá en la Argentina.» Coloquio 43, (2017): 1-10. Acceso el 21 de junio de 2019. http://congresojudio.org/ coloquio_nota.php?id=296.

Raschella, Roberto., y Mariano Fiszman. La historia que nunca les conté. El libro de Gisela. Polonia, 1943-1944. Buenos Aires: Grupo Editorial Norma, 2005.

Schwarzstein, Dora. «Historia oral y memoria del exilio. Reflexiones sobre los republicanos españoles en la Argentina.» Estudios sobre las Culturas Contemporáneas Vol. III, $\mathrm{n}^{\circ} 9$ (1990): 149-172. Acceso el 10 de noviembre de 2018. https://www. culturascontemporaneas.com/articulos.htm?revista $=7$.

«Entre la tierra perdida y la tierra prestada: refugiados judíos y españoles en la Argentina.» En Historia de la vida privada en la Argentina. La Argentina entre multitudes $y$ soledades. De los años treinta a la actualidad. Directores Fernando Devoto y Marta Madero, 111-139. Buenos Aires: Taurus, 1999.

Silberman de Cywiner, María Esther, comp. Asociación Israelita Sefaradi de Beneficencia de Tucumán. Memoria y testimonios de su fundación y evolución. Tucumán: Instituto de Literatura Española (ILE), Facultad Filosofía y Letras, Universidad Nacional de Tucumán, 2006.

Silberman de Cywiner, María Esther, comp. El patrimonio olvidado, Identidad y memoria. Tucumán: Universidad Nacional de Tucumán, 2012. 
Senkman, Leonard. Argentina, la Segunda Guerra Mundial y los refugiados indeseables 1933-1945. Buenos Aires: Grupo Editor Latinoamericano, 1991.

- «La Argentina neutral de 1940 ante los refugiados españoles y judíos.» Ciclos, Año V, Vol. V, n ${ }^{\circ} 9$ (1995): 53-75. http://bibliotecadigital.econ.uba.ar/download/ ciclos/ciclos_v5_n9_03.pdf

Traverso, Enzo. El final de la modernidad judía. Historia de un giro conservador. Buenos Aires: Fondo de Cultura Económica, 2014.

Ulreich, Carry. Sueños de paz. Los diarios de una niña judía que sobrevivió al horror nazi. 1941-1949. Estados Unidos de América: HarperCollins Español, 2018.

Unger, Eugenia. Holocausto. Lo que el tiempo no borró. Buenos Aires: Distal, 1996.

Veil, Simone. Una vida. Buenos Aires: Capital Intelectual, 2010.

Visacovsky, Nerina. Argentinos, judíos y camaradas. Tras la utopía socialista. Buenos Aires: Editorial Biblos, Colección La Argentina Plural, 2015.

Wang, Diana. Los niños escondidos. Del Holocausto a Buenos Aires. Buenos Aires: Marea Editorial, 2018 [Primera edición 2004].

Wechsler, Wanda. «La historia de la memoria del Holocausto en Argentina.» Cuadernos Judaicos, $\mathrm{n}^{\circ} 35$ (2018): 261-280. DOI: https://doi.org/10.5354/0718-8749.2018.52026.

\section{Citar este artículo}

Teitelbaum, Vanesa. "Migración en tiempos de la Segunda Guerra Mundial. El caso de una mujer judía a Tucumán.» Historia Y MEMORIA, n 22 (2021): 285-321. DOI: https:/doi. org/10.19053/20275137.n22.2021.9764. 